\title{
Knowledge on management of traumatic dental injuries among Saudi mothers
}

This article was published in the following Dove Press journal:

Clinical, Cosmetic and Investigational Dentistry

\author{
Fares S Al-Sehaibany' \\ Reem Alajlan ${ }^{2}$ \\ Danah Almubarak ${ }^{2}$ \\ Nassr Almaflehi ${ }^{3}$ \\ Aljazi Aljabaa' \\ Sahar F AIBarakati' \\ 'Department of Pediatric Dentistry \\ and Orthodontics, College of \\ Dentistry, King Saud University, \\ Riyadh, Saudi Arabia; ${ }^{2}$ College of \\ Dentistry, King Saud University, \\ Riyadh, Saudi Arabia; ${ }^{3}$ Department \\ of Periodontics and Community \\ Dentistry, College of Dentistry, King \\ Saud University, Riyadh, Saudi Arabia
}

Correspondence: Fares S Al-Sehaibany Department of Pediatric Dentistry and Orthodontics, College of Dentistry, King Saud University, PO Box 60169, Riyadh

I I545, Saudi Arabia

Tel +966 II 46774 I I

Email falsehaibany@ksu.edu.sa
Objective: This study investigated the knowledge of Saudi mothers regarding the management of traumatic dental injuries (TDIs) in children.

Materials and methods: A cross-sectional study using structured questionnaires was employed for mothers chosen by stratified-cluster random sampling technique from primary health care centers in Riyadh, Saudi Arabia, over a period of 12 months (July 2016-June 2017). The questionnaire surveyed mothers' background and knowledge on management of tooth fracture and avulsion using photographs of TDI cases.

Results: The sample consisted of 3,367 Saudi mothers. More than half of the mothers $(55.3 \%)$ gave the correct response, which was to send the child with tooth fracture immediately to the dentist $(p<0.01)$. The majority of mothers $(41.6 \%)$ gave the correct response for the immediate mode of action, which was to save the avulsed tooth in storage medium and send the child to the dentist immediately $(p<0.001)$. However, they prioritized the immediate management of TDIs, and most reported saline as a suitable storage medium $(p<0.001)$. The mothers expressed a positive interest in further education.

Conclusion: Educational programs and TDI protocols must be implemented to increase mothers' awareness and improve the prognosis of children with TDIs.

Keywords: mothers, knowledge, traumatic dental injuries

\section{Introduction}

One of the most common dental problems seen in children is injury to both primary and permanent dentition and supporting structures, typically caused by accidental falls. ${ }^{1,2}$ Such injuries are disturbing experiences that affect both children and the parent or caregiver, whose ability to manage such problems requires adequate understanding, the immediate exercise of judgment, and prompt action. Both the parent or caregiver (through their prompt response) and the pediatric dentist who sees the child play an important role in restoring oral and emotional health. The management of these children is perhaps unmatched by any other segment of dental practice. ${ }^{3,4}$ Furthermore, execution of proper advice and correct immediate management by mothers present at the accident site will strongly affect the prognosis of such traumatic dental injuries (TDIs).

In response to a lack of adequate awareness and management skills, it has been widely advocated to educate both caregivers and people who are in close proximity to accident sites. ${ }^{5,6}$ Children are likely to spend about $60 \%$ of their time at home rather than in school or at the playground. ${ }^{7}$ Accordingly, it is important to consider the mother of the injured child, in most cases, as the first person to attend to the child and 
make decisions. Even when an accident occurs in a school environment, it is the responsibility of the school authorities to inform the parent of the accident; in such cases, adequate knowledge of how to address such situations on the part of both the school personnel and the parent can substantially reduce the stress of a TDI. The results of a cross-sectional study conducted in Abha, Saudi Arabia, revealed that the surveyed parents had a poor understanding of avulsion; ${ }^{8}$ that said, the study had a small sample size and did not take socioeconomic characteristics into account. Thus, the aim of this study was to investigate, by means of a structured questionnaire, the knowledge of Saudi mothers regarding the management of TDIs in children.

\section{Materials and methods}

The study protocol and consent form were approved by the Research and Ethics Committee of Human Studies at the College of Dentistry Research Center (FR 0399) of King Saud University, Saudi Arabia. The sample consisted of 3,367 Saudi mothers who attended primary health care centers in Riyadh, Saudi Arabia, over a period of 12 months (July 2016-June 2017). Most Saudi mothers are required to attend these centers for pregnancy follow-ups, regular checkups for infants and children, and vaccinations.

A stratified-cluster random sampling technique was used to select the required sample. The city of Riyadh was divided into 5 regions. The study sample was recruited from mothers attending 3 primary health care centers in each region that were randomly selected from the list of primary health care centers obtained from the Ministry of Health, Saudi Arabia. Each mother received a letter explaining the nature of the study, along with an informed consent form, which was signed and returned before the start of the study. Mothers who agreed to participate in the study received a 4-part self-administered questionnaire with questions concerning sociodemographic data, knowledge, and their assessment of photographs of TDI cases. Prior to conducting the study, a permission letter was obtained from the author and publisher of the textbook Essentials of Traumatic Injuries to the Teeth: A Step-by-Step Treatment Guide to utilize TDI photos in this study. ${ }^{9}$

The questionnaire was pretested in a pilot survey among 30 randomly selected mothers who were not included in the main study. The mothers were asked to complete the questionnaire on 2 occasions separated by 1 week. The questionnaire was found to be suitable for application among the study population, as there was a high concurrence with the answers to the questions on both occasions. Cronbach's $\alpha$ was applied for the reliability of the questionnaire and was found to be 0.82 .
The data obtained from the questionnaires were manually entered into the Statistical Package for the Social Sciences (SPSS version 20; IBM Corporation, Armonk, NY, USA) and analyzed at a significance level of $P<0.05$. The Chisquare test was used to identify differences in responses for different variables.

\section{Results}

A total of 3,984 questionnaires were distributed to Saudi mothers, 3,367 of which were completed and returned giving a response rate of $84.5 \%$. The mean $( \pm$ SD) age of the mothers was $32 \pm 9.58$ years. The majority of the mothers were between 25 and 35 years of age (41.7\%) and had a collegelevel education (67.9\%), as presented in Table 1 .

The responses to part II of the questionnaire are presented in Table 2, which concerns questions related to the mothers' awareness and knowledge of TDIs. Most of the mothers had not attended a training course $(70.7 \%)$ or previously received any information about TDIs (63.9\%).

Part III of the questionnaire addressed 2 case scenarios with the help of clinical photographs, as described in Table 3. The first scenario involved an 11-year-old child who had fallen and broken an upper front tooth (Figure 1). The second scenario involved a 9-year-old child who had fallen and had an upper front tooth knocked out (Figure 2). In the first case scenario, the majority of the mothers (55.3\%) gave the correct response, which was to "send the child immediately to the

Table I Responses to part I: personal and professional information about the study population

\begin{tabular}{ll}
\hline Variable & Total, N=3,367, $\mathbf{n}(\%)$ \\
\hline Age (years) & $1,310(38.9)$ \\
$<25$ & $1,407(41.7)$ \\
$25-35$ & $483(14.3)$ \\
$>35-45$ & $167(5.1)$ \\
$>45$ & \\
Marital status & $2,969(88.2)$ \\
$\quad$ Married & $201(6.0)$ \\
Divorced & $197(5.8)$ \\
Widowed & \\
Number of children & $1,416(42.0)$ \\
I & $651(19.4)$ \\
2 & $1,300(38.6)$ \\
3 or more & \\
Level of education & $953(28.3)$ \\
High school & $2,285(67.9)$ \\
College & $129(3.8)$ \\
Higher education & \\
Occupation & $2,503(74.3)$ \\
Unemployed & $545(16.2)$ \\
Government job & $319(9.5)$ \\
Private job &
\end{tabular}


Table 2 Responses to part II: awareness and knowledge regarding TDls of the respondents

\begin{tabular}{ll}
\hline Question & Total, N=3,367, n (\%) \\
\hline QI. Have you witnessed any TDIs in the & \\
past? & \\
Yes & $\mathrm{I}, 822(54.0)$ \\
No & $\mathrm{I}, 545(46.0)$ \\
Q2. Have you ever attended a TDls & \\
education course? & \\
Yes & $987(29.3)$ \\
No & $2,380(70.7)$ \\
Q3. Have you obtained information about & \\
TDls previously? & \\
Yes & $1,216(36.1)$ \\
No & $2,151(63.9)$ \\
Q4. If yes, source of information: & \\
Dentist & $1,616(48.0)$ \\
Physician & $269(8.0)$ \\
Friend & $340(10.1)$ \\
Internet/social network & $974(28.9)$ \\
Other & $168(5.0)$ \\
\hline
\end{tabular}

Abbreviation: TDI, traumatic dental injury.

dentist," while almost half of the mothers ( $46.1 \%)$ believed it was not necessary to save the broken piece of tooth, and this was statistically significant $(p<0.01$ and $p<0.05$, respectively).

In the second case scenario, the majority of mothers (41.6\%) gave the correct response for the immediate mode of action, which was to "save the knocked-out tooth in storage medium and send the child to the dentist immediately" and to "immediately replant the knocked-out tooth" (46\%), and this was statistically significant $(p<0.001)$. A statistically significant difference was observed in the storage medium most suitable for storing the knocked-out tooth reported by nearly one-third of the mothers $(31.8 \%)$ as normal saline $(p<0.001)$. However, $42.9 \%$ of the mothers incorrectly responded that the knocked-out tooth was most likely a baby tooth, and this result was statistically significant $(p<0.01)$.

The final part of the questionnaire assessed the mothers' interest in managing and learning more about TDIs. The mothers were not confident in their ability to manage a TDI, with the majority $(64.3 \%)$ admitting that they would be incapable of doing so, and most were willing to receive further information about TDIs (83.9\%) as presented in Table 4.

\section{Discussion}

This cross-sectional study was conducted to investigate the level of knowledge of Saudi mothers regarding management of TDIs in children. The majority of the mothers surveyed were of childbearing age, between 25 and 35 years of age (41.7\%), had a college education (67.9\%), and were
Table 3 Responses to part III: case scenarios

\begin{tabular}{|c|c|}
\hline Question & $\begin{array}{l}\text { Total, } \mathbf{N}=3,3 \\
\text { n (\%) }\end{array}$ \\
\hline \multicolumn{2}{|c|}{$\begin{array}{l}\text { Case I: an II-year-old child fell and broke an upper front tooth } \\
\text { (Figure I): }\end{array}$} \\
\hline \multicolumn{2}{|c|}{ QI. Should the broken piece of the tooth be saved? } \\
\hline a. Yes & $\mathrm{I}, 043(31.0)$ \\
\hline b. No & $\mathrm{I}, 552(46.1)^{*}$ \\
\hline c. I don't know & $772(22.9)$ \\
\hline \multicolumn{2}{|l|}{ Q2. Immediate action should be: } \\
\hline a. Send the child immediately to the dentist & $\mathrm{I}, 862(55.3)^{* *}$ \\
\hline b. Put the child to bed & $1,252(37.2)$ \\
\hline c. I don't know & $253(7.5)$ \\
\hline
\end{tabular}

Case II: a 9-year-old child fell down and the upper front tooth got knocked out (Figure 2):

QI. What will be your immediate action?

a. Replant the tooth and send the child to the 387 (II.5)
dentist

b. Save it in storage medium and send the child $\quad$ I,40I (4I.6)*** to the dentist

c. Stop the bleeding and have the child rest 929 (27.6)

d. Not sure what to do 650 (19.3)

Q2. The knocked-out tooth is likely to be:

$\begin{array}{ll}\text { a. Baby tooth } & \mathrm{I}, 447(42.9)^{* * *} \\ \text { b. Permanent tooth } & \mathrm{I}, \mathrm{I} \text { I2(33.0) } \\ \text { c. I don't know } & 808(24.1)\end{array}$

Q3. Which storage medium is suitable for storing the knocked-out tooth?

$\begin{array}{ll}\text { a. Tap water } & 75 I(22.3) \\ \text { b. Antiseptic solution } & 303(9.0) \\ \text { c. Tissue paper } & 636(18.9) \\ \text { d. Milk } & 606(18.0) \\ \text { e. Normal saline } & \text { I,07I (3I.8)*** }\end{array}$

Q4. How soon should the knocked-out tooth be replanted?

\begin{tabular}{ll} 
a. Immediately & $\mathrm{I}, 549(46.0)^{* * * *}$ \\
b. Within 30 minutes & $498(14.8)$ \\
c. Within a few hours & $848(25.2)$ \\
d. By the next day & $472(14.0)$ \\
\hline
\end{tabular}

Note: $* P<0.05 ; * * P<0.01 ; * * * P<0.001$, from $\chi^{2}$ test.

unemployed (74.3\%). The latter implies the majority of mothers were available to their children at all times at home and were available to provide first aid if an unfortunate incident of dental trauma were to occur.

Fifty-four percent of the mothers admitted having witnessed TDIs in the past. This is comparatively lower than that reported in the study among mothers in the United Arab Emirates. ${ }^{10}$ In this study, a majority of the mothers (70.7\%) had not attended any formal training course about TDIs, and $63.9 \%$ had not previously received any information about TDIs. Despite their lack of training, Saudi mothers were aware of the importance of immediately treating TDIs, unlike the UAE mothers. ${ }^{10}$ An Indian study reported that most of the 


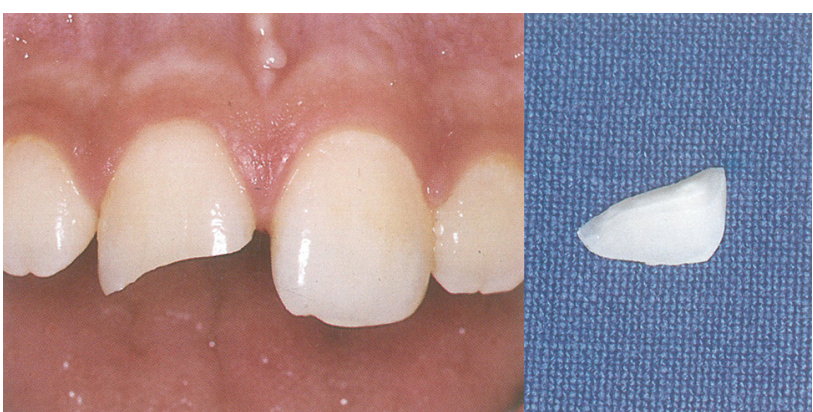

Figure I Crown fracture of maxillary right permanent central incisor.

Notes: Adapted with permission from Andreasen JO, Andreasen FM. Essentials of Traumatic Injuries to the Teeth: A Step-by-Step Treatment Guide. Hoboken, NJ: John Wiley \& Sons; 2010 . Copyright (C) 2000 J.O. Andreasen, F.M. Andreasen and Munksgaard. 9

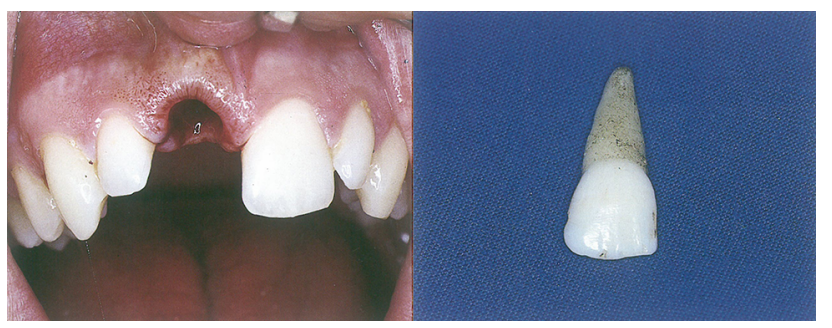

Figure 2 Avulsion of maxillary right permanent central incisor.

Notes: Adapted with permission from Andreasen JO, Andreasen FM. Essentials of Traumatic Injuries to the Teeth: A Step-by-Step Treatment Guide. Hoboken, NJ: John Wiley \& Sons; 20I0. Copyright (c) 2000 J.O. Andreasen, F.M. Andreasen and Munksgaard. 9

Table 4 Responses to part IV: responses to questions regarding management of TDls and further education

\begin{tabular}{ll}
\hline Questions & $\begin{array}{l}\text { Total, N=3,367, } \\
\mathbf{n}(\%)\end{array}$ \\
\hline $\begin{array}{l}\text { QI. Are you capable of managing a TDI if it } \\
\text { happens? }\end{array}$ & \\
a. Yes & $\mathrm{I}, 202(35.7)$ \\
b. No & $2,165(64.3)$ \\
Q2. How important is it to learn about TDIs? & \\
a. Very important & $2,820(83.7)$ \\
b. Important & $489(14.6)$ \\
c. Not important & $58(1.7)$ \\
Q3. Would you like to receive information about & \\
TDIs? & \\
a. Yes & $2,827(83.9)$ \\
b. No & $540(16.1)$ \\
\hline
\end{tabular}

Abbreviation: TDI, traumatic dental injury.

mothers surveyed were college graduates and were aware of the emergency management of TDIs regardless of whether they were employed. ${ }^{11}$

Part III of the questionnaire addressed 2 case scenarios likely to be faced by mothers at home which were presented as simple, concise, and closed-ended questions. Several studies in the dental literature have focused on the parental knowledge of management of avulsion, ${ }^{12-14}$ whereas other studies have included wider aspects of dental trauma. ${ }^{15,16} \mathrm{In}$ most of these studies, the parental knowledge of management of TDIs or only avulsion was deficient, so the need for public awareness of TDIs and their management has been emphasized.

In the first case scenario, which concerned an 11-yearold child who had fallen and broken an upper front tooth, the respondents were unaware of the importance of saving the broken piece of tooth. There are 2 main reasons that the broken piece of tooth must be saved and taken to the dentist with little delay, and this urgency was correctly acknowledged by the majority of the respondents. The most important reason is to ensure that the child has not aspirated the tooth fragment, which would require a chest radiograph to ascertain. Second, it may be possible to bond the tooth fragment to the remaining tooth.

The second case scenario was related to management of an avulsed upper front tooth in a 9-year-old child. The basic knowledge that a 9-year-old child has permanent upper front teeth was correctly answered by only $33 \%$ of the mothers; this response is lower than that in a similar study among Jordanian mothers. ${ }^{17}$ Although a significantly higher proportion of mothers identified the knocked-out tooth as a baby tooth, which was incorrect, most of the mothers knew that the tooth should be saved in storage medium and that the child should be sent immediately to the dentist for replantation. Although intrinsic factors of each individual may affect the prognosis of traumatized teeth, evidence-based specific storage media are indicated in circumstances where the time period since trauma has been long, such as Hank's balanced salt solution or the tooth rescue box, the latter contains a culture medium comprising amino acids, vitamins, and glucose.$^{18}$ However, among the storage media readily available at the time of dental trauma such as milk, water, saliva, or saline, pasteurized milk has been considered most favorable. ${ }^{19}$ Furthermore, a study regarding the knowledge of tooth avulsion and its management among dental assistants in Riyadh, which involved a large proportion of females, reported milk to be the best or most suitable storage medium. ${ }^{20}$ It was assumed that mothers would generally choose milk as the most suitable storage medium, as it is readily available at home, but in this survey, only $18 \%$ of the mothers selected milk - most $(31.8 \%)$ selected saline. This is in accordance with the study conducted among school nurses in which $82 \%$ reported saline as the recommended storage medium. ${ }^{21}$

More than $64 \%$ of the respondents stated that they were not capable of managing an incident of TDI. Furthermore, more than $83 \%$ of the respondents wanted to receive further 
information about TDIs, which is encouraging. Certain limitations of this study merits mention in order to improve on future studies. First, being a questionnaire-based survey, there might be some elements of underreporting bias in the study. The cross-sectional study design and nonrespondent bias may be considered as other drawbacks. The knowledge about TDIs among parents, in general, was not investigated. We assumed that majority of the mothers spend more time with their children and play an important role in decision-making, if an incident of TDI was to occur. Therefore, the decision was made to investigate mothers' knowledge regarding TDIs.

The results of this study may help in making strategic plans to enhance the knowledge of mothers about TDIs and its management along with the awareness of long-term consequences following the dental traumatic incident. For instance, oral education programs in the form of seminars, workshops, and distribution of flyers/posters with algorithm for decision-making process may be initiated during pregnancy follow-ups, regular checkups for infants and children, and vaccination appointments.

\section{Conclusion}

In general, Saudi mothers lack knowledge of identifying the proper dentition involved in dental trauma, whether a primary or a permanent tooth is involved, and the importance of saving the fractured tooth fragment. These results suggest that there is a need for effective TDI educational programs to be delivered to primary health care centers in Riyadh, which mothers in this survey considered valuable and relevant.

\section{Acknowledgments}

The authors thank Dr Nouf Al-Samari for her assistance in data entry. The authors also extend their appreciation to the College of Dentistry Research Center and Deanship of Scientific Research at King Saud University, Saudi Arabia, for funding this study.

\section{Disclosure}

The authors report no conflicts of interest in this work.

\section{References}

1. McTigue DJ. Diagnosis and management of dental injuries in children. Pediatr Clin North Am. 2000;47(5):1067-1084.

2. Bastone EB, Freer TJ, McNamara JR. Epidemiology of dental trauma: a review of the literature. Aust Dent J. 2000;45(1):2-9.
3. Hegde R, Agrawal G. Prevalence of traumatic dental injuries to the permanent anterior teeth among 9- to 14-year-old schoolchildren of Navi Mumbai (Kharghar-Belapur region), India. Int J Clin Pediatr Dent. 2017;10(2):177-182.

4. McIntyre JD, Lee JY, Trope M, Vann WF Jr. Effectiveness of dental trauma education for elementary school staff. Dent Traumatol. 2008;24(2):146-150.

5. Hamilton FA, Hill FJ, Mackie IC. Investigation of lay knowledge of the management of avulsed permanent incisors. Endod Dent Traumatol. 1997;13(1):19-23.

6. Raphael SL, Gregory PJ. Parental awareness of the emergency management of avulsed teeth in children. Aust Dent J. 1990;35(2):130-133.

7. Gupta K, Tandon S, Prabhu D. Traumatic injuries to the incisors in children of South Kanara District. A prevalence study. J Indian Soc Pedod Prev Dent. 2002;20(3):107-113.

8. AlGhamdi NMS, Alothman SA, Assiri AM, Bijle MNA, Togoo RA. Knowledge of Saudi parents toward the emergency management of avulsed permanent teeth: a cross-sectional survey. J Dent Res Rev. 2016;3(3):85-87.

9. Andreasen JO, Andreasen FM. Essentials of Traumatic Injuries to the Teeth: A Step-by-Step Treatment Guide. Hoboken, NJ: John Wiley \& Sons; 2010.

10. Hashim R. Investigation of mothers' knowledge of dental trauma management in United Arab Emirates. Eur Arch Paediatr Dent. 2012;13(2):83-86.

11. Hegde A, Pradeep Kumar K, Varghese E. Knowledge of dental trauma among mothers in Mangalore. Dent Traumatol. 2010;26(5):417-421.

12. Nikam AP, Kathariya MD, Chopra K, Gupta A, Kathariya R. Knowledge and attitude of parents/caretakers toward management of avulsed tooth in Maharashtrian Population: a questionnaire method. J Int Oral Health. 2014;6(5):1-4.

13. Loo TJ, Gurunathan D, Somasundaram S. Knowledge and attitude of parents with regard to avulsed permanent tooth of their children and their emergency management-Chennai. J Indian Soc Pedod Prev Dent. 2014;32(2):97-107.

14. Ozer S, Yilmaz EI, Bayrak S, Tunc ES. Parental knowledge and attitudes regarding the emergency treatment of avulsed permanent teeth. Eur J Dent. 2012;6(4):370-375.

15. Vergotine RJ, Koerber A. The relationship of dental visits to parental knowledge of management of dental trauma. Pediatr Dent. 2010;32(4):329-332.

16. Sae-Lim V, Chulaluk K, Lim LP. Patient and parental awareness of the importance of immediate management of traumatized teeth. Endod Dent Traumatol. 1999;15(1):37-41.

17. Al-Jundi SH. Knowledge of Jordanian mothers with regards to emergency management of dental trauma. Dent Traumatol. 2006;22(6): 291-295.

18. Brunet-Llobet L, Lahor-Soler E, Miranda-Rius J. Replantation of an avulsed tooth after one day of storage in adverse extraoral dry conditions: acceptable outcome after a 10-year follow-up. Quintessence Int. 2018;49(1):25-31.

19. de Souza BD, Bortoluzzi EA, Reyes-Carmona J, et al. Effect of temperature and seven storage media on human periodontal ligament fibroblast viability. Dent Traumatol. 2017;33(2):100-105.

20. Halawany HS, AlJazairy YH, Alhussainan NS, AlMaflehi N, Jacob V, Abraham NB. Knowledge about tooth avulsion and its management among dental assistants in Riyadh, Saudi Arabia. BMC Oral Health. 2014;14:46

21. Baginska J, Wilczynska-Borawska M. Knowledge of nurses working at schools in Bialystok, Poland, of tooth avulsion and its management. Dent Traumatol. 2012;28(4):314-319. 


\section{Publish your work in this journal}

Clinical, Cosmetic and Investigational Dentistry is an international, peer-reviewed, open access, online journal focusing on the latest clinical and experimental research in dentistry with specific emphasis on cosmetic interventions. Innovative developments in dental materials, techniques and devices that improve outcomes and patient satisfaction and preference will be highlighted. The manuscript management system is completely online and includes a very quick and fair peerreview system, which is all easy to use. Visit http://www.dovepress. com/testimonials.php to read real quotes from published authors.

Submit your manuscript here: https://www.dovepress.com/clinical-cosmetic-and-investigational-dentistry-journal 